\title{
A case of discordance between genotype and phenotype in a malignant hyperthermia family
}

\author{
Giuliana Fortunato ${ }^{1}$, Antonella Carsana ${ }^{1}$, Nadia Tinto ${ }^{1}$, Virginia Brancadoro ${ }^{2}$, \\ Giovanna Canfora ${ }^{2}$ and Francesco Salvatore ${ }^{1}$ \\ ${ }^{1}$ Dipartimento di Biochimica e Biotecnologie Mediche, Università Federico II di Napoli, and CEINGE Biotecnologie \\ Avanzate, Napoli, Italy \\ ${ }^{2}$ Cattedra di Anestesia e Rianimazione, Università Federico II di Napoli, Napoli, Italy
}

\begin{abstract}
Malignant hyperthermia (MH) is an inherited autosomal dominant pharmacogenetic disorder and is the major cause of anaesthesia-induced death. Malignant hyperthermia susceptibility is usually diagnosed by the in vitro contracture test (IVCT) performed on fresh muscle biopsies exposed to caffeine and halothane, respectively. Around $50 \%$ of affected families are linked to the ryanodine receptor $(R Y R 1)$ gene. The human $R Y R 1$ gene maps to chromosome 19q13.1 and encodes a protein that associates as a homotetramer and acts as a calcium-release channel from the sarcoplasmic reticulum. To date, 17 mutations have been identified in the coding region of the RYR1 gene and appear to be associated to the MH-susceptible phenotype. Here we describe a rare case of discordance between genotype (characterised by the presence of the Arg614Cys mutation in the RYRI gene) and MH-normal typed phenotype. Although the IVCT remains a very reliable procedure for the assessment of MH status, genetic data can provide in some cases an additional aid to clinical diagnosis.
\end{abstract}

Keywords: malignant hyperthermia; in vitro contracture test; ryanodine receptor; genotype/phenotype discordance

\section{Introduction}

Malignant hyperthermia ( $\mathrm{MH})$ is an inherited autosomal dominant pharmacogenetic disorder and is the major cause of anaesthesia-induced death. The symptoms of an $\mathrm{MH}$ attack, triggered by widely used inhalational anaesthetics and depolarizing muscle relaxants, are muscle rigidity, accelerated metabolism, contractures, hyperthermia and tachycardia. Malignant hyperthermia susceptibility (MHS) can be diagnosed

Correspondence: Professor Francesco Salvatore, Dipartimento di Biochimica e Biotecnologie Mediche, Università Federico II di Napoli, Via S Pansini 5, 80131 Napoli, Italy. Tel: + (39) 081 7464966; Fax: + (39) 081 7463650; E-mail: salvator@unina.it

Received 31 August 1998; revised 2 December 1998; accepted 15 December 1998 by the in vitro contracture test (IVCT) performed on fresh muscle biopsies exposed to caffeine and halothane, respectively. ${ }^{1}$ Malignant hyperthermia has a considerable genetic heterogeneity; only about $50 \%$ of affected families are linked to the ryanodine receptor ( $R Y R 1$ ) gene. The human $R Y R 1$ gene maps to chromosome $19 \mathrm{q} 13.1$ and encodes a protein that associates as a homotetramer and acts as a calcium-release channel from the sarcoplasmic reticulum (see Mickelson and Louis $^{2}$ for review).

To date, 17 mutations have been identified in the coding region of the $R Y R 1$ gene., All the mutations appear to be associated to the MHS phenotype, identified by the IVCT, although there are some reports of discordance between genotype and phenotype. ${ }^{4-8}$ Furthermore, other $\mathrm{MH}$ loci have been mapped to 
chromosomes $3 \mathrm{q}, 7 \mathrm{q}$ and $17 \mathrm{q}^{2}$ and recently to chromosomes $1 \mathrm{q}$ and $5 \mathrm{p} .{ }^{9}$ Regarding the locus on chromosome 1 , a mutation in the CACNL1AS gene, which encodes the $\alpha 1$-subunit of the skeletal muscle dihydropyridine receptor, is associated with the MHS phenotype in a large family. ${ }^{10}$ Co-segregation of the MHS phenotype with a polymorphic microsatellite DNA marker, adjacent to the gene of the $\alpha 2 / \delta$-subunit of the dihydropyridine receptor, which maps to chromosome 7q21-22, was reported in one German pedigree. ${ }^{11}$ No mutations in this gene have yet been described. Recently, linkage analysis in a family in which both hyperkalemic periodic paralysis and $\mathrm{MH}$ were inherited as autosomal-dominant traits, indicates a probable association of $\mathrm{MH}$ to the adult skeletal muscle sodium channel $(S C N 4 A)$ gene on chromosome $17 .^{12}$ The candidate genes for the other $\mathrm{MH}$ loci have not yet been identified.

Here we report a rare case of discordance between genotype, characterised by the presence of the Arg614Cys mutation in $R Y R 1$, and $\mathrm{MH}$-normal typed phenotype, in a family from the South of Italy Malignant Hyperthermia Centre.

\section{Patients and Methods}

The family NA-1 was referred to the South of Italy Malignant Hyperthermia Centre because subject 2 of the pedigree (see Figure 1), the proband, had a severe MH attack, characterised by generalised muscle rigidity and tachyarrhythmias, during anaesthesia for appendectomy. Seven members of the family underwent the standardised European IVCT; ${ }^{1}$ the conditions of muscle fibers were: twitch $2.5-16.6 \mathrm{~g}$, weight $0.15-0.2 \mathrm{~g}$,

\section{NA-1 FAMILY}

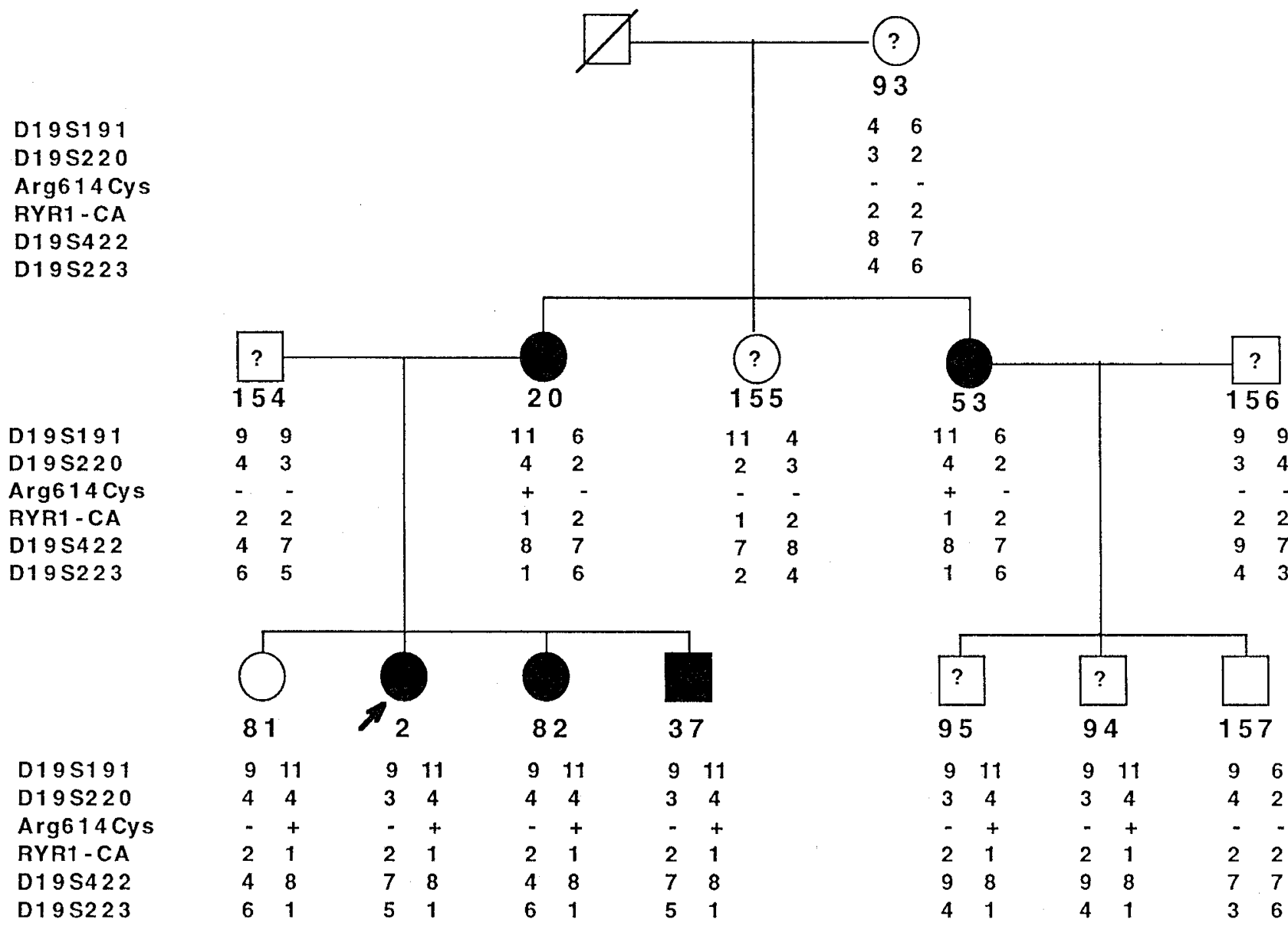

Figure 1 Pedigree of the NA-1 family, showing chromosome 19q linkage markers and RYR1 Arg614Cys mutation data, listed on the left aligned with the numbered alleles found in each individual. Solid symbols: MHS individuals identified by the IVCT; open symbols: individuals MHN typed by the IVCT; ?: untested members of the pedigree; +/-: presence or absence of the Arg614Cys mutation. The arrow indicates the index case who experienced an MH episode. 
length $1.5-2.5 \mathrm{~cm}$. All the tests were performed within 1-3 hours of the biopsy. A force increase of at least $0.2 \mathrm{~g}$ following either $2 \%$ halothane or $2 \mathrm{~mm}$ caffeine is required to score a sample as MHS. Contraction threshold at higher concentrations than these were considered normal. The conditions of the muscle of subject 81 were comparable with all the other subjects of the family and within the limits assigned by the European criteria as indicated above. Individual 81 was never exposed to anaesthetic agents.

DNA was extracted from $10 \mathrm{ml}$ of two independent whole blood samples collected from each subject and screened for the Arg163Cys, Gly341Arg, Arg614Cys, Arg614Leu, Arg2163Cys, Arg2163His, Val2168Met and Gly2435Arg mutations as previously described. ${ }^{13-17}$ The DNA was sequenced by fluorescent dye-terminator cycle sequencing on an automated sequencer (ABI 373A, Applied Division, Perkin Elmer, Foster City, CA, USA). The microsatellite repeat markers for loci D19S191, D19S220, RYR1-CA, D19S422 and D $19 S 223^{18}$ were typed by PCR amplification in a $25 \mu \mathrm{l}$ reaction volume containing $100 \mathrm{ng}$ of genomic DNA, $0.1 \mu \mathrm{mol} / \mathrm{l}$ of each primer, $0.2 \mathrm{mmol} / 1 \mathrm{dNTPs}, 10 \mathrm{mmol} / \mathrm{l}$ Tris$\mathrm{HCl}, \mathrm{pH} 8.3$ at $25^{\circ} \mathrm{C}, 50 \mathrm{mmol} / 1 \mathrm{KCl}, 1.5 \mathrm{mmol} / 1 \mathrm{MgCl}_{2}$, $0.001 \%$ gelatin $(\mathrm{w} / \mathrm{v}), 1.5 \mu \mathrm{Ci}$ of $\alpha^{32} \mathrm{P}$ dATP $(3000 \mathrm{Ci} / \mathrm{mmol})$ and $0.02 \mathrm{U} / \mu \mathrm{l}$ of Taq polymerase. After $5 \mathrm{~min}$ incubation at $95^{\circ} \mathrm{C}$, the samples were subjected to 35 cycles of $45 \mathrm{~s}$ at $94^{\circ} \mathrm{C}$, $45 \mathrm{~s}$ at the annealing temperature $\left(42^{\circ} \mathrm{C}\right.$ for D19S422, $46^{\circ} \mathrm{C}$ for D19S191, D19S220 and D19S223, $54^{\circ} \mathrm{C}$ for RYR1-CA) and $45 \mathrm{~s}$ at $72^{\circ} \mathrm{C}$, followed by a final extension step at $72^{\circ} \mathrm{C}$ for $5 \mathrm{~min}$. Marker alleles were separated on $4 \%$ polyacrylamide sequencing gels, detected by autoradiography and typed as described elsewhere. ${ }^{18}$

\section{Results and Discussion}

Thirteen individuals of the NA-1 family were screened for eight of the most frequent RYR1 mutations (Arg163Cys, Gly341Arg, Arg614Cys, Arg614Leu, Arg2163Cys, Arg2163His, Val2168Met and Gly2435Arg).
Only the Arg614Cys mutation was detected by restriction analysis and segregates with the MHS phenotype (see Figure 1), identified by the IVCT, in all the tested subjects. Direct DNA sequencing of PCR products from three heterozygous subjects (individuals 2, 20 and 53) and from the homozygous subject 155 confirmed that the loss of the RsaI restriction site was the result of a $1840 \mathrm{C} \rightarrow \mathrm{T}$ transition (Arg-Cys amino acid exchange). Mutation Arg614Cys was also detected in individual 81 of the NA-1 family who was negative at the IVCT (Table 1), and confirmed by direct sequencing of PCR products (Figure 2). The pedigree was then typed with five polymorphic microsatellite markers of chromosome 19 (D19S191, D19S220, RYR1-CA, D19S422 and D19S223, in genetic order) and unequivocal haplotypes were constructed. The five MHS individuals share haplotype 11-4-1-8-1, not present in the MH-normal (MHN) individual 157. On the contrary, subject 81 , MHN according to the IVCT, bears the haplotype found in the MHS subjects of the pedigree studied.

The discordance observed between genotype and phenotype in subject 81 can be explained:

(i) by inexact genotypic characterisation,

(ii) by inexact phenotypic characterisation, or

(iii) by incomplete penetrance of the Arg614Cys mutation.

The presence of the mutation in individual 81 was detected by restriction enzyme analysis and confirmed by direct DNA sequencing of the PCR product on two independent DNA samples collected at different times,

Table 1 Results of the in vitro contracture test (IVCT) in the NA-1 family

\begin{tabular}{|c|c|c|c|c|c|c|c|c|c|c|c|c|c|}
\hline \multirow{4}{*}{ Individuals } & \multicolumn{3}{|c|}{ Static halothane $^{a}$} & \multicolumn{3}{|c|}{ Dynamic halothane $^{a}$} & \multicolumn{6}{|c|}{ Caffeine $^{\mathrm{b}}$} & \multirow[t]{4}{*}{ Diagnosis } \\
\hline & \multirow{3}{*}{$\begin{array}{l}\text { Threshold* } \\
\%\end{array}$} & \multirow{3}{*}{\multicolumn{2}{|c|}{$\begin{array}{c}\text { Contracture }(g) \\
\text { at threshold at } 2 \%\end{array}$}} & \multirow{3}{*}{$\begin{array}{l}\text { Threshold* } \\
\%\end{array}$} & \multirow{2}{*}{\multicolumn{2}{|c|}{$\begin{array}{c}\text { Contracture }(g) \\
\text { at threshold at } 2 \%\end{array}$}} & \multirow{2}{*}{\multicolumn{2}{|c|}{$\begin{array}{l}\text { Threshold* } \\
\text { mmoml/l }\end{array}$}} & \multicolumn{4}{|c|}{ Contracture $(g)$} & \\
\hline & & & & & & & & & at thre. & & at $2 \mathrm{mn}$ & & \\
\hline & & & & & & & I & II & I & II & I & II & \\
\hline 20 & 1.5 & 0.4 & 0.7 & n.d. & n.d. & 0.1 & 1.5 & 4 & 0.2 & 4 & 0.3 & -0.4 & MHS \\
\hline 53 & 1 & 0.7 & 1.4 & 1 & 0.6 & 2.9 & 1.5 & 1.5 & 0.2 & 0.2 & 0.9 & 0.5 & MHS \\
\hline 81 & 4 & 0.25 & -0.6 & n.d. & n.d. & 0.0 & 4 & 4 & 0.7 & 1.6 & -0.3 & -0.1 & MHN \\
\hline 2 & 0.5 & 1 & 1.6 & 0.5 & 0.8 & 2.2 & 1 & 1 & 0.3 & 0.2 & 0.8 & 0.4 & MHS \\
\hline 82 & 1 & 0.2 & 1.2 & 1 & 0.35 & 0.9 & 1 & 2 & 0.35 & 0.3 & 0.7 & 0.3 & MHS \\
\hline 37 & 0.5 & 1 & 2.2 & 0.5 & 0.2 & 9.4 & 0.5 & 1.5 & 0.2 & 1.3 & 2 & 2.1 & MHS \\
\hline 157 & n.d. & n.d. & -0.2 & n.d. & n.d. & -0.2 & $>4$ & 4 & n.d. & 0.2 & -0.25 & -0.35 & MHN \\
\hline
\end{tabular}

${ }^{\mathrm{a}}$ Static halothane and caffeine tests are performed at optimal length of fibre bundle, while in the dynamic halothane test the length of the fibre bundle is cyclically changed.

${ }^{\mathrm{b}}$ The results obtained on two different fibres are reported.

${ }^{c}$ Threshold at which a contraction $0.2 \mathrm{~g}$ in muscle fibre was obtained. n.d. = not determined 

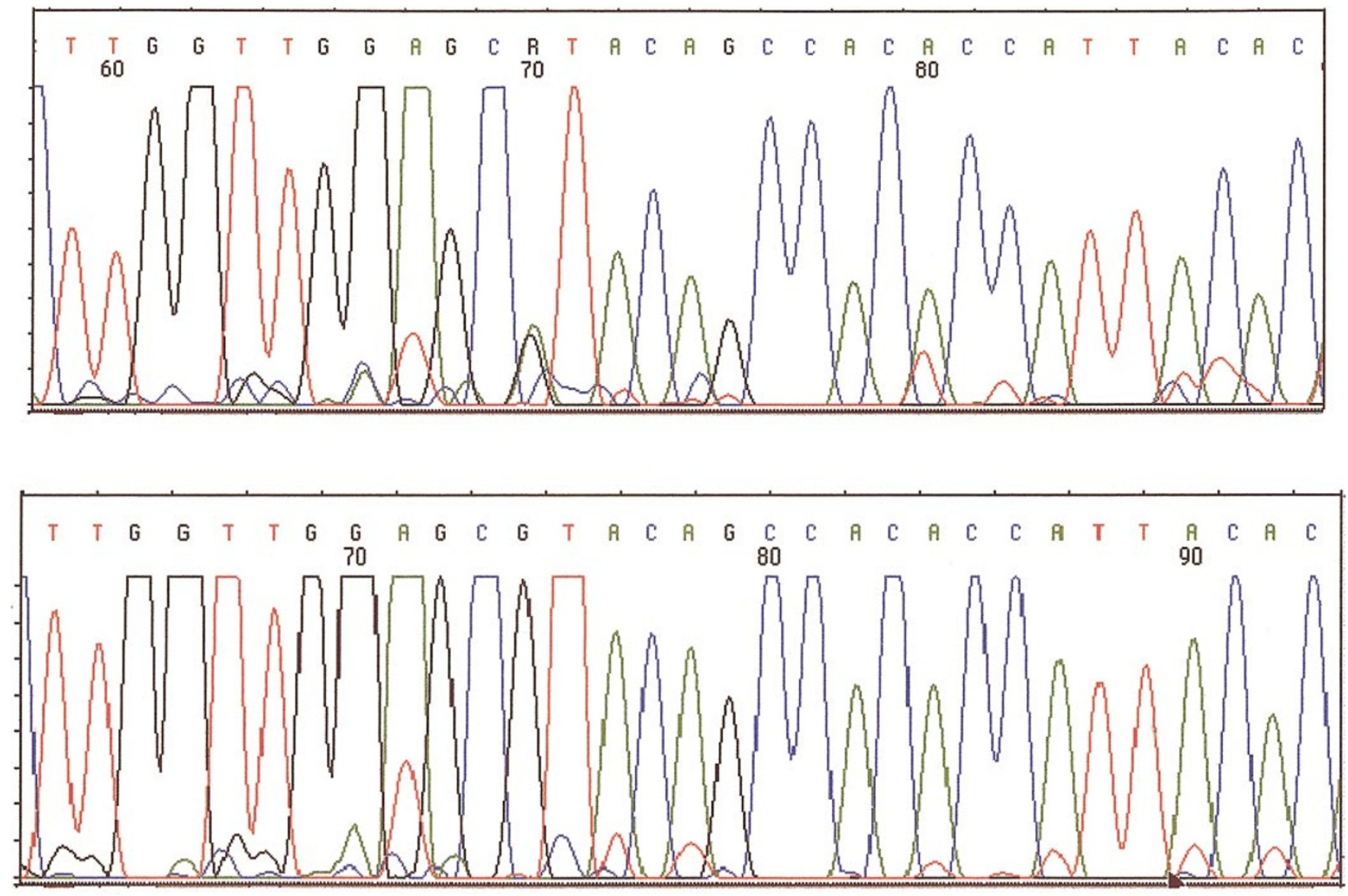

Figure 2 Identification of the 1840C->T transition at the etherozygous status in the RYR1 gene in subject 81 (upper panel) by sequence analysis. The sequence of the individual 155 (lower panel, wild type sequence) is reported as a comparison. The DNA sequence of non-coding strand is given. Lettering above each graph refers to the base identified by the sequencer, ' $R$ ' denotes the simultaneous presence of both $G$ and $A$, which corresponds to the $1840 C->T$ transition in the complementary strand.

thus rendering the first hypothesis highly unlikely. In addition, the presence of the mutation correlates with the presence of a specific chromosome $19 \mathrm{q}$ haplotype, which is absent from individuals who do not carry the substitution. As to the second hypothesis, it is noteworthy that the clinical diagnostic parameters of the IVCT were established to privilege diagnostic sensitivity $(99 \%)$ rather than diagnostic specificity $(93.6 \%) .{ }^{19}$ Nevertheless, four cases of patients who were MH-normal according to the IVCT and later had an $\mathrm{MH}$ attack, were reported from the same laboratory, ${ }^{20}$ although it may be questioned if cases described are truly false negative. In any case, it is not possible to exclude completely inexact phenotype characterisation. Regarding the third hypothesis, it has been demonstrated that the Arg614Cys mutation exerts a functional effect on the ryanodine receptor RYR1. In fact, sarcoplasmic reticulum vesicles from MHS pigs, carrying a mutation corresponding to the human Arg614Cys mutation, have a higher affinity for ryanodine and are more sensitive to the effect of 4-chloro-m-cresol or caffeine on ryanodine binding than are MHN vesicles. ${ }^{21}$ Furthermore, the presence of this mutation in the recombinant rabbit RYR1 expressed in transfected COS- $7,{ }^{22}$ myoblastic $\mathrm{C}_{2} \mathrm{C}_{12}{ }^{23}$ or HEK- $293^{3}$ cells causes abnormal cytosolic $\mathrm{Ca}^{2+}$ release in response to the exogenous activators 4-chloro-m-cresol, ${ }^{22}$ or caffeine and halothane, ${ }^{3,23}$ respectively. Moreover, there was a close correlation between the results of cellular $\mathrm{Ca}^{2+}$ photometry and of clinical IVCT used to evaluate the caffeine sensitivity of different RYR1 mutants. ${ }^{3}$ Taken together these considerations seem to preclude an incomplete penetrance of the mutation, although it cannot be ruled out that additional mutations in RYRI 
or in other MH loci may modify the phenotypic effect of $R Y R 1$ mutations in MH families.

Some cases of discordance between genotype and phenotype have been described ${ }^{4-8}$ and they mainly concern discrepancies between MHS IVCT results and the absence of the mutation. ${ }^{4-6,8}$ The only other instance of an MHN individual bearing the Arg614Cys mutation was reported by Deufel et al. ${ }^{7}$ The authors suggested that their results may challenge the causative role of this mutation. Since then there is increasing evidence $^{3,21}$ that the Arg614Cys substitution results in altered functionality of the RYR1 protein. Moreover, Tong $e t a l^{3}$ proposed that once a mutation has been shown in vitro to confer a higher sensitivity than the wild type to the $\mathrm{Ca}^{2+}$-releasing effects of caffeine and halothane, the individual carrying such a mutation should be considered MH-susceptible. In conclusion, also on the basis of the foregoing observations, although typed MHN, subject 81 should be regarded as MHS for clinical purposes, since she bears the mutation, and has a high risk familial haplotype. The case described here reinforces the notion that genetic data for MH status can in some cases provide additional diagnostic information, although obviously it cannot replace the IVCT.

\section{Acknowledgements}

This work was supported by grants from Progetto Finalizzato Biotecnologie (CNR, Rome) and Comitato Biotecnologie e Biologia molecolare (CNR, Rome), the Regione Campania and Ministero Università e Ricerca Scientifica e Tecnologica (MURST, PRIN 1997). We thank Dr C Fumo for her help in performing some preliminary experiments. We are indebted to Jean Gilder for editing the text.

\section{References}

1 European Malignant Hyperthermia Group: Malignant hyperpyrexia: a protocol for the investigation of malignant hyperthermia. Br J Anaesth 1984; 56: 1267-1269.

2 Mickelson JR, Louis CF: Malignant hyperthermia: excitation-contraction coupling, $\mathrm{Ca}^{+2}$ release channel, and cell $\mathrm{Ca}^{+2}$ regulation defects. Physiol Rev 1996; 76: 537-592.

3 Tong J, Oyamada H, Demaureux N, Grinstein S, McCarthy TV, MacLennan DH: Caffeine and halothane sensitivity of intracellular $\mathrm{Ca}^{2+}$ release is altered by 15 calcium release channel (ryanodine receptor) mutations associated with malignant hyperthermia and/or central core disease. J Biol Chem 1997; 272: 26332-26339.
4 MacLennan DH: Discordance between phenotype and genotype in malignant hyperthermia. Curr Opin Neurol 1995; 8: 397-401.

5 Serfas KD, Bose D, Patel L et al: Comparison of the segregation of the RYR1 C1840T mutation with segregation of the caffeine/halothane contracture test results for malignant hyperthermia susceptibility in a large Manitoba Mennonite family. Anesthesiology 1996; 84: 322-329.

6 Adeokun AM, West SP, Ellis FR et al: The G1021A substitution in the $R Y R 1$ gene does not cosegregate with malignant hyperthermia susceptibility in a British pedigree. Am J Hum Genet 1997; 60: 833-841.

7 Deufel T, Sudbrak R, Feist Y et al: Discordance, in a malignant hyperthermia pedigree, between in vitro contracture-test phenotypes and haplotypes for the MHS1 region on chromosome 19q12-13.2, comprising the C1840T transition in the RYR1 gene. Am J Hum Genet 1995; 56: 1334-1342.

8 Fagerlund TH, Ording H, Bendixen D et al: Discordance between malignant hyperthermia susceptibility and RYR1 mutation C1840T in two Scandinavian $\mathrm{MH}$ families exhibiting this mutation. Clin Genet 1997; 52: 416-421.

9 Robinson RL, Monnier N, Wolz W et al: A genome wide search for susceptibility loci in three European malignant hyperthermia pedigrees. Hum Mol Genet 1997; 6: 953-961.

10 Monnier N, Procaccio V, Stieglitz P, Lunardi J: Malignanthyperthermia susceptibility is associated with a mutation of the $\alpha 1$-subunit of the human dihydropyridine-sensitive L-type voltage-dependent calcium-channel receptor in skeletal muscle. Am J Hum Genet 1997; 60: 1316-1325.

11 Iles DE, Lehmann-Horn F, Scherer SW et al: Localization of the gene encoding the $\alpha 2 / \delta$-subunit of the L-type voltage-dependent calcium channel to chromosome $7 q$ and analysis of the segregation of flanking markers in malignant hyperthermia susceptible families. Hum Mol Genet 1994; 3: 969-975.

12 Moslehi R, Langlois S, Yam I, Friedman JM: Linkage of malignant hyperthermia and hyperkalemic periodic paralysis to the adult skeletal muscle sodium channel $(S C N 4 A)$ gene in a large pedigree. Am J Med Genet 1998; 76 21-27.

13 Quane KA, Healy JMS, Keating KE et al: Mutations in the ryanodine receptor gene in central core disease and malignant hyperthermia. Nat Genet 1993; 5: 51-5.

14 Alestrom A, Fagerlund TH, Berg K: A simple method to detect the RYR1 mutation G1021A, a cause of malignant hyperthermia susceptibility. Clin Genet 1995; 47: 274-275.

15 Otsu K, Phillips S, Khanna VK, de Leon S, MacLennan $\mathrm{DH}$ : Refinement of diagnostic assays for a probable causal mutation for porcine and human malignant hyperthermia. Genomics 1992; 13: 835-837.

16 Keating KE, Quane KA, Manning BM et al: Detection of a novel RYR1 mutation in four malignant hyperthermia pedigrees. Hum Mol Genet 1994; 3: 1855-1858.

17 Manning BM, Quane KA, Ording H et al: Identification of novel mutations in the ryanodine-receptor gene (RYRI) in malignant hyperthermia: genotype-phenotype correlation. Am J Hum Genet 1998; 62: 599-609.

18 Dib C, Fauré S, Fizames C et al: A comprehensive genetic map of the human genome based on 5,264 microsatellites. Nature 1996; 380: A112-115. 
19 Ording $\mathrm{H}$ for the European Malignant Hyperthermia Group: In vitro contracture test for diagnosis of malignant hyperthermia following the protocol of the European MH Group: results of testing patients surviving fulminant $\mathrm{MH}$ and unrelated low-risk subjects. Acta Anesthesiol Scand 1997; 41: 955-966.

20 Isaacs $\mathrm{H}$, Badenhorst $\mathrm{M}$ : False negative results with muscle caffeine halothane contracture testing for malignant hyperthermia-susceptible and normal muscle. Biochem Pharmacol 1993; 79: 5-9.

21 Hermann-Frank A, Richter M, Lehmann-Horn F: 4-chloro-m-cresol: a specific tool to distinguish between malignant hyperthermia-susceptible and normal muscle. Biochem Pharmacol 1996; 52: 149-155.
22 Treves S, Larini F, Menegazzi $\mathrm{P}$ et al: Alteration of intracellular $\mathrm{Ca}^{2+}$ transients in COS-7 cells transfected with the cDNA encoding skeletal-muscle ryanodine receptor carrying a mutation associated with malignant hyperthermia. Biochem J 1994; 301: 661-665.

23 Otsu K, Nishida K, Kimura Y et al: The point mutation Arg615->Cys in the $\mathrm{Ca}^{+2}$ release channel of skeletal sarcoplasmic reticulum is responsible for hypersensitivity to caffeine and halothane in malignant hyperthermia. $J$ Biol Chem 1994; 269: 9413-9415. 